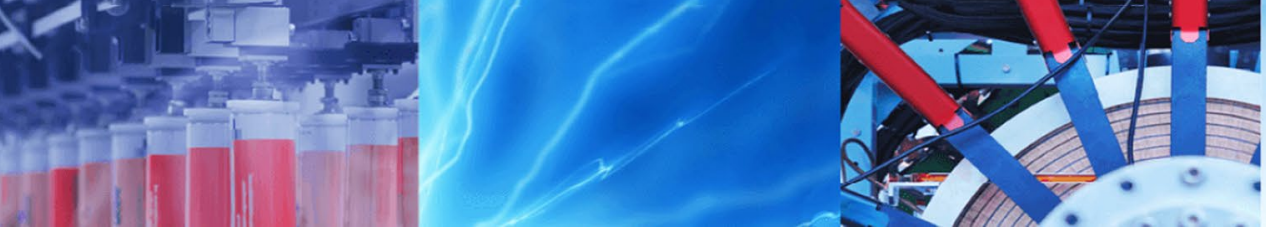

Research Article

\title{
Chromium (VI) removal from neutral aqueous media using banana trunk fibers (BTF)-reinforced chitosan-based film, in comparison with BTF, chitosan, chitin and activated carbon
}

\author{
Muhammad Rahim ${ }^{1}$ (D) Mas Rosemal Hakim Mas Haris ${ }^{1}$
}

(c) Springer Nature Switzerland AG 2019

\begin{abstract}
Banana trunk fibers (BTF)-reinforced chitosan (BTF-i-CTS) biocomposite film was prepared and characterized by means of Fourier-transform infrared spectroscopy, thermogravimetric analysis and scanning electron microscopy. Characterization of the starting materials and the biocomposite indicated that BTF are widely immobilized in chitosan (CTS) by physical means. The water uptake results of BTF-i-CTS indicated a maximum water uptake of $338.23 \%$ with an equilibrium time of $72 \mathrm{~h}$. The starting materials and BTF-i-CTS in comparison with chitin and activated carbon (AC) were used for the removal of $\mathrm{Cr}^{6+}$. The effect of $\mathrm{pH}$, contact time and initial concentration was investigated. Contact time of $120 \mathrm{~min}$ and pH of $\sim 7.00$ were selected for the removal of $\mathrm{Cr}^{6+}$, at ambient temperature $\left(27 \pm 1^{\circ} \mathrm{C}\right)$. The percentage removal of $\mathrm{Cr}^{6+}$ at $\mathrm{pH} \sim 7.00$ and initial concentration of $50 \mathrm{mg} / \mathrm{L}$ using BTF-i-CTS, CTS, BTF, chitin and AC was observed 97.79, 97.78, 25.79, 36.80 and $23.78 \%$, respectively. The data best-fitted pseudo-second-order kinetic and Freundlich isotherm model indicated that chemisorption is the likely factor for the removal of $\mathrm{Cr}^{6+}$.
\end{abstract}

Keywords Banana trunk fibers · Chitosan · Biocomposite $\cdot$ Chromium (VI) $\cdot$ Sorption

\section{Introduction}

Industrial wastes are the main sources of surface and ground water contamination [1]. Aqueous wastes of metal plating, tanneries, smelting, batteries, mining operation, pesticide and fertilizer industries contain high level of heavy metal ions [2]. Heavy metal ions attracted the attention of researchers in view of their toxicity [3, 4], bioaccumulation, bio-magnification, persistence and non-biodegradability [5]. Several technologies have been used to remove metal ions from industrial aqueous wastes, and sorption is one of the widely practiced processes [6]. Therefore, the removal of metal ions to an optimum level by a cost-effective and eco-friendly manner is of great interest [7].

Chitosan (CTS) is a linear polymer of $\beta(1-4)$-linked $\mathrm{N}$-acetyl-D-glucosamine and D-glucosamine units. It is the second most abundant naturally occurring polymer after cellulose [8]. CTS is the excellent chelating agent with several metal ions [9]. The synthetic derivatives of CTS have been investigated for the removal of several metal ions from aqueous medium. The literature survey indicated that CTS and its derivatives have been reported widely for the sorption of $\mathrm{Cr}(\mathrm{VI})$ [10-16]. However, derivatization of CTS requires equipments, chemicals and sometimes toxic byproducts and the use of organic solvents discourage the technique. The literature study also indicates that inorganic sorbents and $A C$ have been used extensively for the removal of various metal ions [17-23], but the removal of these sorbents from the sorption media is very difficult. Furthermore, the removal of these materials requires either filtration or centrifugation, which are time-consuming and energy-intensive processes. These materials block pores of the filter paper which needs vacuum filtration,

\footnotetext{
$\triangle$ Muhammad Rahim, kpk566@gmail.com | 'School of Chemical Sciences, Universiti Sains Malaysia, 11800 Minden, Pulau Pinang,
} Malaysia.

SN Applied Sciences (2019) 1:1180 | https://doi.org/10.1007/s42452-019-1206-9 
leading to high cost, whereas CTS and BTF are the costeffective, eco-friendly and naturally abundant polymers having great potential toward sorption of several metal ions. Therefore, in this study, a green biocomposite film comprising of BTF-reinforced CTS was prepared and successfully investigated for the removal of $\mathrm{Cr}^{6+}$ from neutral aqueous media.

\section{Materials and methods}

CTS with degree of $\mathrm{N}$-deacetylation $95 \%$ and relative average molecular weight of $1.05 \times 10^{5}$ was supplied by Advanced Materials Research Centre, Kedah, Malaysia. $1000 \pm 2 \mathrm{mg} / \mathrm{L}$ standard solutions of $\mathrm{Cr}^{6+}$ were purchased from Fluka, Switzerland. Water was freshly distilled prior to use.

\subsection{Preparation of BTF-reinforced CTS biocomposite film}

CTS gel was prepared by adding $2.000 \pm 0.005 \mathrm{~g}$ of CTS powder to $100 \mathrm{~mL}$ of $2 \%(\mathrm{v} / \mathrm{v})$ acetic acid aqueous solution. The mixture was stirred using mechanical stirrer for $1 \mathrm{~h}$. Then, $0.200 \mathrm{~g}$ of BTF was added and dispersed by means of a glass rod. The resulting slurry was transferred into a plastic-layered glass petri dish and dried in a convection oven at $60^{\circ} \mathrm{C}$ for $48 \mathrm{~h}$.

\subsection{Activation of charcoal}

Charcoal was placed in a muffle furnace, and the carbonization was carried out at $200^{\circ} \mathrm{C}$ for $24 \mathrm{~h}$. The carbonized material was ground to fine powder. The resulting material was placed in an air-tight container for further studies [24].

\subsection{Characterization}

Brunauer-Emmett-Teller (BET) surface area and pore size of the materials were determined by a quantachrome NOVA-2200e instrument. The materials were degassed at $110^{\circ} \mathrm{C}$ and exposed to constant cryogenic liquid nitrogen $\left(-197.3^{\circ} \mathrm{C}\right)$ at a series of precisely controlled pressures. The gas adsorption isotherms were obtained by plotting the volume of gas $\left(\mathrm{cm}^{3} / \mathrm{g}\right)$ against $P / P_{o}$ (relative pressure). Surface area and the types of pores were predicted from the shape of the isotherms.

The FT-IR spectra of the starting materials (CTS and BTF) and BTF-i-CTS were obtained by PerkinElmer Spotlight-200 spectrophotometer. Attenuated total reflection (ATR) technique was used to scan the samples at room temperature $\left(27+1^{\circ} \mathrm{C}\right)$. The background spectrum was obtained before running the sample. The scanning resolution and the number of scans were adjusted $4 \mathrm{~cm}^{-1}$ and 16 , respectively. The samples were scanned in the range of $650-4000 \mathrm{~cm}^{-1}$.

Thermal stability of the starting materials and biocomposite film was determined using PerkinElmer TGA-7 thermogravimetric analyzer. The samples were run under nitrogen atmosphere in the temperature range of $30-900^{\circ} \mathrm{C}$. The temperature was increased slowly with a heating rate of $10^{\circ} \mathrm{C} / \mathrm{min}$. The thermograms were obtained by plotted weight loss (\%) against temperature $\left({ }^{\circ} \mathrm{C}\right)$.

The surface morphology of the biocomposite film was determined using Leo Supra 50Vp Field Emission Scanning Electron Microscope (FESEM). The biocomposite film was dried in oven at $60^{\circ} \mathrm{C}$ for $24 \mathrm{~h}$, coated onto gold foil and observed in the microscope under vacuum using Turbopump: Varian VT-300-HT.

\subsection{Batch sorption experiments}

\subsubsection{Sorption kinetics}

$\mathrm{Cr}^{6+}$ solution $(50 \mathrm{mg} / \mathrm{L})$ was prepared by dilution technique using standard solution of $1000 \pm 2 \mathrm{mg} / \mathrm{L}$. Batch sorption kinetics tests were conducted by mixing $0.200 \pm 0.009 \mathrm{~g}$ of the sorbent with $50 \mathrm{~mL}$ of $\mathrm{Cr}^{6+}$ ion solutions ( $\mathrm{pH} \sim 2.00$, 4.00, 6.00 and 7.00) in an Erlenmeyer flask. The flasks were agitated using orbital shaker (KS 130 Basic) with a speed of $300 \mathrm{rpm}$. The $\mathrm{pH}$ was adjusted using either $0.1 \mathrm{M}$ solution of $\mathrm{NaOH}$ or $\mathrm{HCl}$. After predetermined time intervals, the solution was pipette out and concentration was determined using atomic absorption spectrometer (PerkinElmer AAnalyst 400). The experiments were conducted in triplicate at $27 \pm 1^{\circ} \mathrm{C}$. For the comparison, CTS, BTF, chitin and $A C$ were also investigated for the removal of $\mathrm{Cr}^{6+}$ at the same conditions. The percentage removal and sorption capacity $(\mathrm{mg} / \mathrm{g})$ were determined using the following Eqs. 1 and 2, respectively [25].

$\%$ removal $=\frac{C_{0}-C_{t}}{C_{0}} \times 100$

Sorption Capacity $=\frac{\left(C_{0}-C_{\mathrm{e}}\right)}{M} \times V$

where $C_{0}$ is the initial concentration $(\mathrm{mg} / \mathrm{L}), C_{\mathrm{t}}$ is the concentration $(\mathrm{mg} / \mathrm{L})$ in the solution at time ' $t$ ' and $C_{e}$ is the concentration ( $\mathrm{mg} / \mathrm{L}$ ) at equilibrium. $V$ is the volume of solution in liter, and $M$ is the mass of adsorbent in grams.

Pseudo-first- and second-order kinetic models were applied to find out the possible kinetic of the adsorption process, as shown in Eqs. 3 and 4, respectively [26].

$\log \left(q_{\mathrm{e}}-q_{\mathrm{t}}\right)=\log q_{\mathrm{e}}-\left(\frac{k_{1}}{2.303}\right) t$ 
$\frac{t}{q_{\mathrm{t}}}=\frac{1}{k_{2} q_{\mathrm{e}}^{2}}+\left(\frac{1}{q_{\mathrm{e}}}\right) t$

where $q_{\mathrm{e}}$ and $q_{\mathrm{t}}$ are the concentrations of metal ions at equilibrium and time' $t$ ', respectively.

\subsubsection{Adsorption isotherm}

In order to find out the possible sorption isotherm, $\mathrm{Cr}^{6+}$ solutions $(1,5,10,20$ and $50 \mathrm{mg} / \mathrm{L})$ were prepared and the $\mathrm{pH}$ was adjusted $\sim 7.00$. Batch isotherm experiments were conducted by mixing $0.2 \mathrm{~g}$ of either biocomposite film, CTS, BTF, chitin or AC with different concentration solutions (1-50 mg/L). The mixture was agitated, and the supernatant was analyzed for the residual metal ion concentrations. Freundlich and Langmuir isotherm models were applied to the experimental data to find out the sorption isotherm, as shown in Eqs. 5 and 6, respectively [27].

$\frac{C_{\mathrm{e}}}{q_{\mathrm{e}}}=\frac{C_{\mathrm{e}}}{q_{\mathrm{m}}}+\frac{1}{q_{\mathrm{m}} b}$

$q_{\mathrm{e}}=k_{\mathrm{F}} C_{\mathrm{e}}^{\frac{1}{n}}$

where $q_{\mathrm{e}}(\mathrm{mg} / \mathrm{g})$ and $C_{\mathrm{e}}(\mathrm{mg} / \mathrm{L})$ are the amounts of adsorbed metal ions and remaining concentration, respectively. $q_{\mathrm{m}}$ is the maximum amount of the metal ion sorbed, and $b$ is a constant related to the affinity of the binding sites (L/mg). $k_{\mathrm{F}}$ and $n$ are the Freundlich constants, which indicate adsorption capacity and intensity, respectively.

\subsubsection{Point of zero charge (PZC)}

Point of zero charge (PZC) was determined using solid addition method [28]. The initial $\mathrm{pH}\left(\mathrm{pH}_{\mathrm{i}}\right)$ of the solutions was adjusted between 2 and 10 by adding either $0.5 \mathrm{M} \mathrm{HCl}$ or $\mathrm{NaOH} . \mathrm{pH}_{\mathrm{i}}$ of the solutions were accurately noted, and $0.1 \mathrm{~g}$ of the sorbent was added to the series of different $\mathrm{pH}_{\mathrm{i}}$ solutions. The solutions were kept for $24 \mathrm{~h}$. Then, final $\mathrm{pH}\left(\mathrm{pH}_{\mathrm{f}}\right)$ was determined. The difference between $\mathrm{pH}_{\mathrm{i}}$ and $\mathrm{pH}_{\mathrm{f}}$ was calculated. The difference was plotted against $\mathrm{pH}$, and the required PZC was obtained [29].

\section{Results and discussion}

\subsection{FT-IR analysis}

The FT-IR spectra of CTS, BTF and biocomposite film are shown in Fig. 1. The spectra are assigned as reported in the literature $[30,31]$. The spectrum of biocomposite film (curves $b$ ) showed that there is no alteration of bands, and neither appearance of new bands nor disappearance of the existing bands. These results indicated that BTF are not grafted but widely immobilized within CTS by physical means which was further supported by TGA analysis.

\subsection{Thermal stability analysis}

The thermogravimetric (TG) and derivative thermogravimetric (DTG) thermograms of starting materials and biocomposite film are shown in Fig. 2. CTS indicated two-step decomposition process. The first-step decomposition in the temperature of $40-115^{\circ} \mathrm{C}$ indicated the liberation of volatile compounds and absorbed water molecules. The second-step rapid decomposition with a weight loss of $58.1 \%$ occurred in the temperature range of $257-465^{\circ} \mathrm{C}$. The second-step thermal decomposition indicated cleavage and chain scission of $\mathrm{C}-\mathrm{C}$ and $\mathrm{C}-\mathrm{O}$ bonds of the CTS monomer units [32]. The DTG thermogram of CTS
Fig. 1 FT-IR spectra of: CTS (a), BTF-i-CTS (b) and BTF(c)

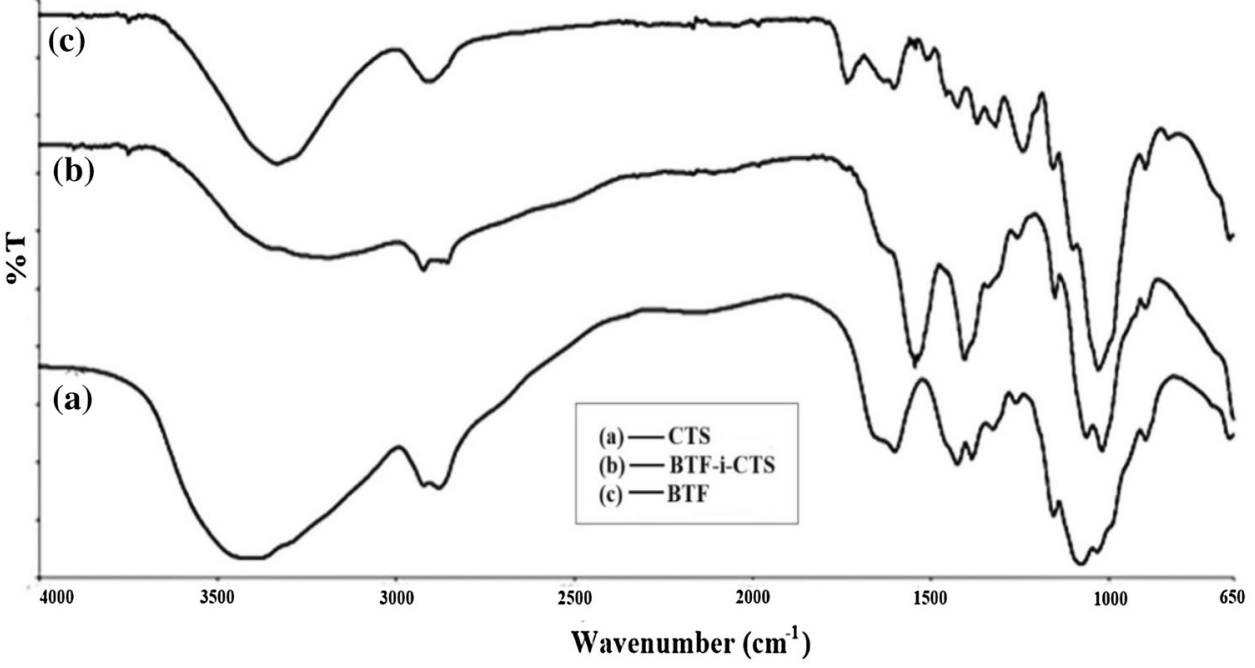

SN Applied Sciences 
Fig. 2 TG and DTG thermograms of CTS, BTF and BTF-iCTS

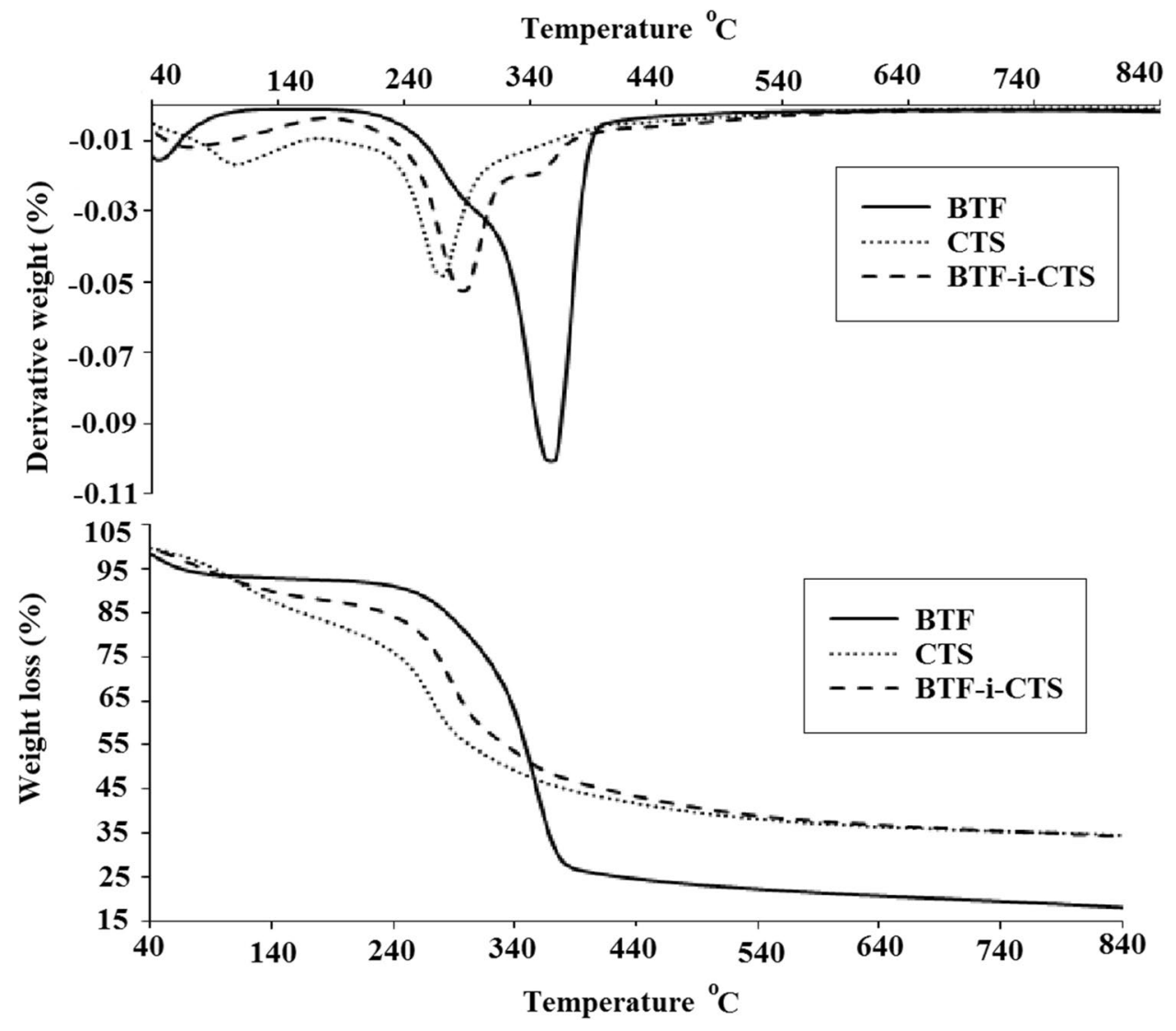

indicated $309.26^{\circ} \mathrm{C}$ as the main decomposition temperature. TGA thermograms of BTF indicated a fast decomposition of $74 \%$ in the temperature range of $247-396^{\circ} \mathrm{C}$. The thermal decomposition of BTF is most likely due to the decomposition of hemicellulosics in an inert atmosphere [33]. The DTG thermogram of BTF indicates two main decomposition temperatures $\left(54.37\right.$ and $360.90^{\circ} \mathrm{C}$ ). The first peak might be due to moisture, whereas the second peak is most probably due to cellulose and lignin decomposition. The thermal decomposition of biocomposite film indicated two peaks. The first major peak is due to the thermal decomposition of CTS, while the second minor peak is attributed to BTF. These results indicated that BTF have been widely immobilized within CTS by physical means.

\subsection{Surface morphology}

Scanning electron microscopy was used to investigate the surface of biocomposite film. The SEM images of the biocomposite film are shown in Fig. 3. The images showed almost smoother surface of the biocomposite film indicated well dispersion followed by entrapment of BTF within CTS.

\section{4 $\mathrm{Cr}^{6+}$ sorption studies}

\subsubsection{Effect of $\mathrm{pH}$ and contact time}

The $\mathrm{pH}$ of solution has significant impact on the uptake of metal ions, and therefore, the effect of $\mathrm{pH}$ on adsorption of $\mathrm{Cr}^{6+}$ ion was studied. Initial metal ion concentration and sorbent dose were chosen $50 \mathrm{mg} / \mathrm{L}$ and $0.2 \mathrm{~g}$, respectively. The $\mathrm{pH}$ was adjusted from 2 to 7 . However, in acidic $\mathrm{pH}$, $\mathrm{Cr}^{6+}$ converts to $\mathrm{Cr}^{3+}$ [34]. The effect of $\mathrm{pH}$ and contact time on the percent removal of $\mathrm{Cr}^{6+}$ onto the biocomposite at a temperature of $27 \pm 1{ }^{\circ} \mathrm{C}$ is shown in Fig. 4.

The point of zero charge for CTS, chitin, BTF, BTF-i-CTS and $A C$ was found to be 3.9, 4.1, 4.6, 4.2 and 5.3, respectively, as shown in Fig. 5. At this point, surface of the sorbent has net zero charge and the sorbent surface shows amphoteric properties at this point. As such, the surface of the sorbent has a net negative surface charge at $\mathrm{pH}>\mathrm{PZC}$, whereas it has a net positive surface charge, if $\mathrm{pH}<\mathrm{PZC}$ [35]. PZC provides useful information on the ability of sorbent surface to adsorb metal ions [36]. As such, the "Effect of $\mathrm{pH}^{\prime \prime}$ results indicated that the sorption capacities of the materials are higher in $\mathrm{pH}$ above 4.0 , while $\mathrm{Cr}^{6+}$ converts to $\mathrm{Cr}^{3+}$ in acidic $\mathrm{pH}$ [34]. Therefore, $\mathrm{pH} \sim 7.00$ was chosen as the optimum $\mathrm{pH}$ for the rest of the experiments, whereas 

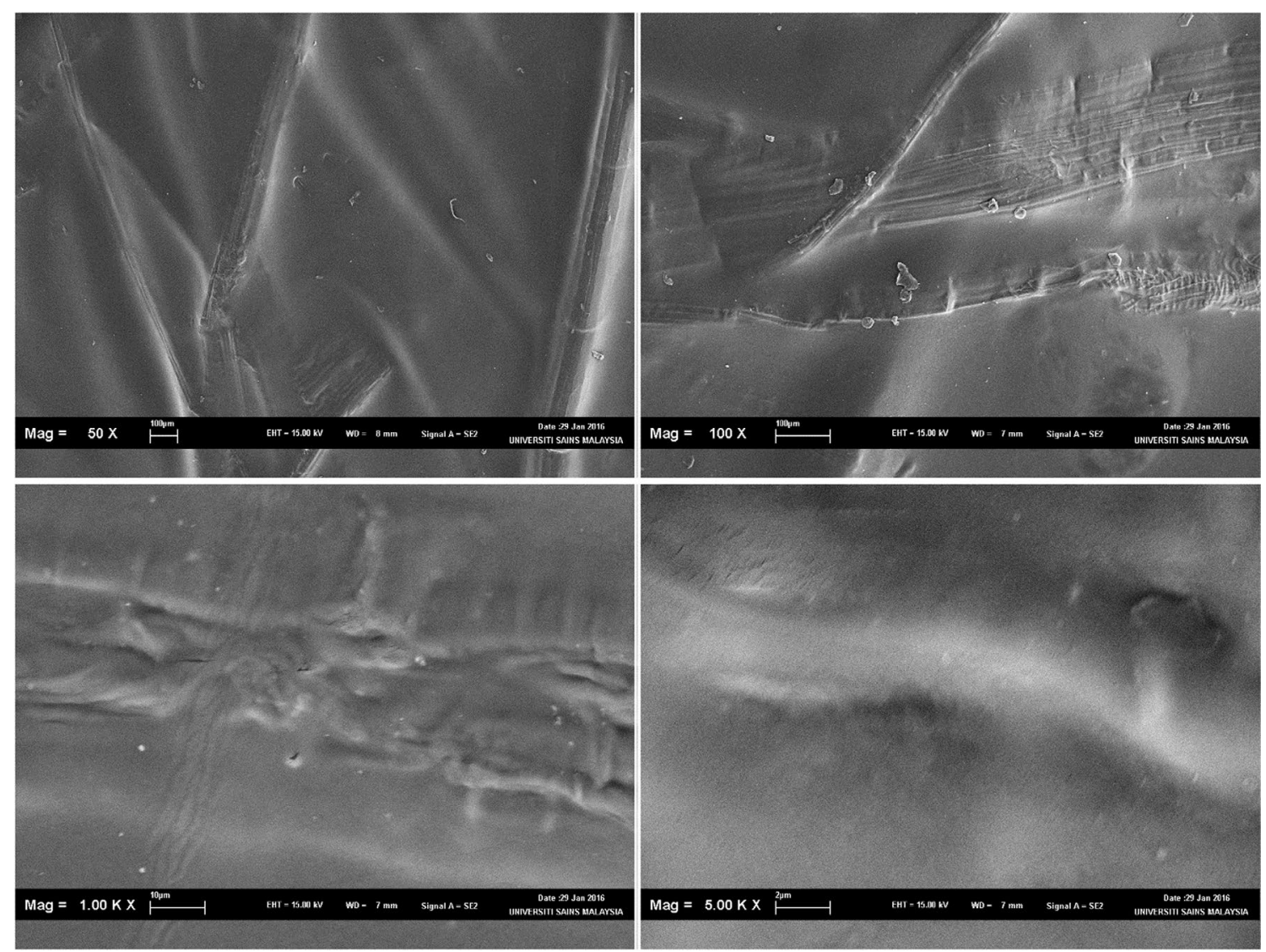

Fig. 3 SEM images of BTF-i-CTS biocomposites

Fig. 4 Effect of $\mathrm{pH}$ and contact time on percent removal of $\mathrm{Cr}^{6+}$ onto biocomposite

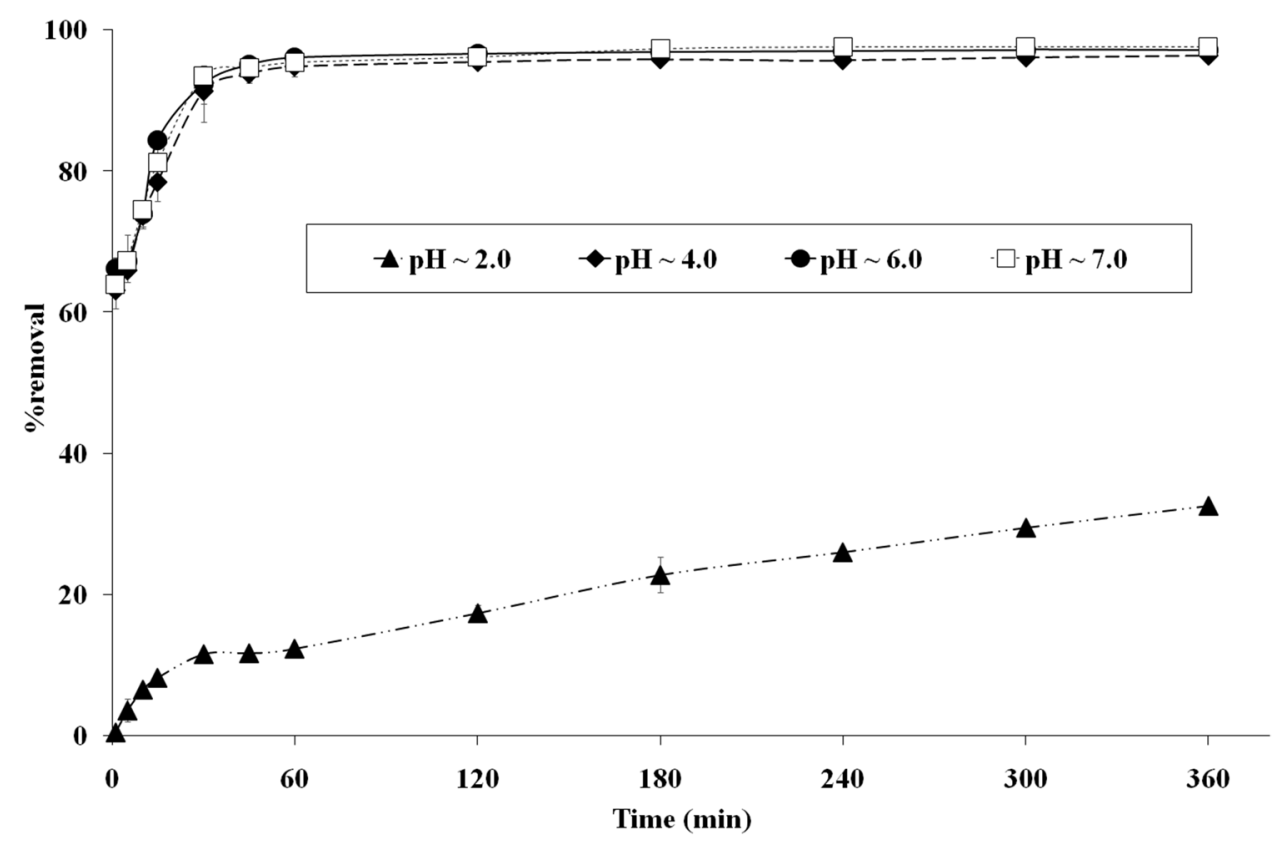


Fig. 5 Point of zero charge (PZC) of CTS, chitin, BTF, BTF-iCTS and AC

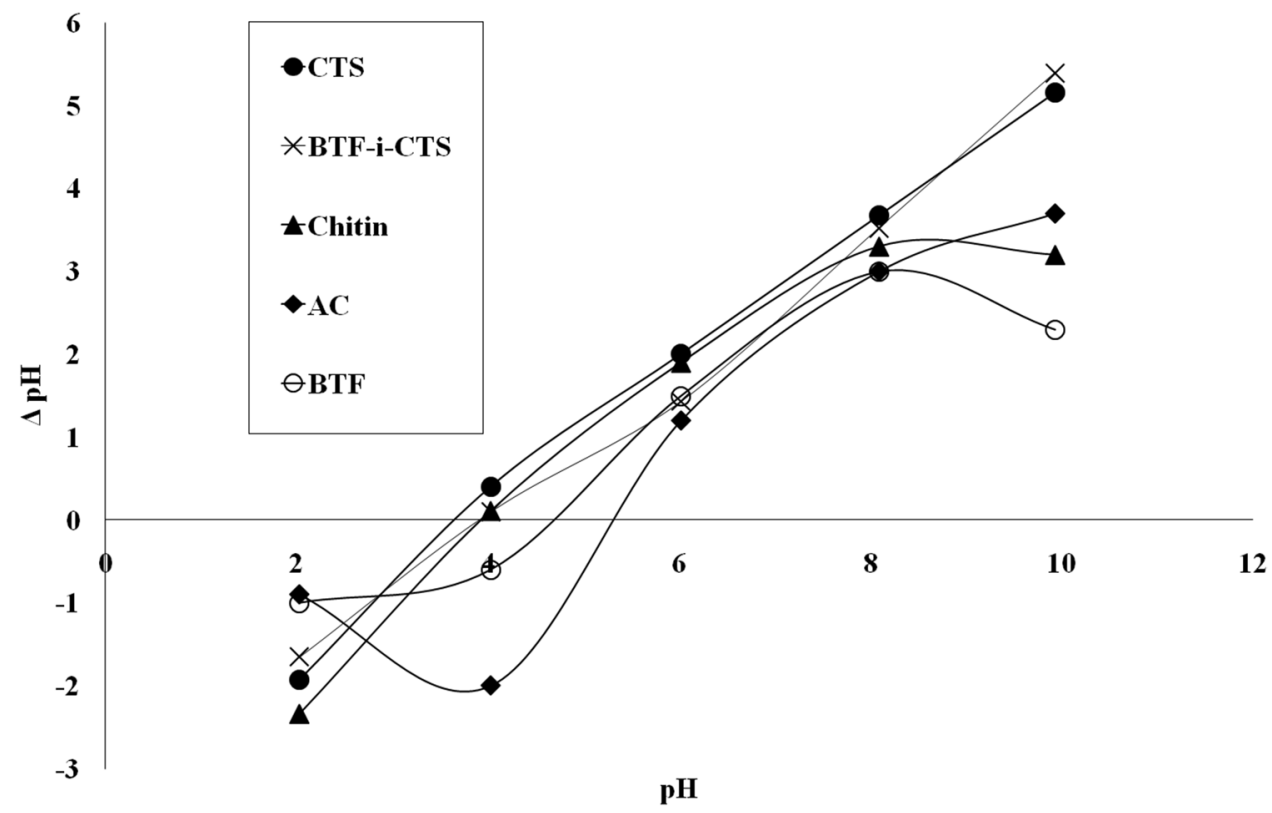

the $\mathrm{pH}$ was monitored during experimental work. As such, the $\mathrm{pH}$ change was observed to a maximum of \pm 0.7 , which has no effect on the oxidation state of $\mathrm{Cr}$.

The literature survey indicates that the adsorption of metal ions is greater at low $\mathrm{pH}$ and decreases with an increase in $\mathrm{pH}$ [14]. In case of the present study, the biocomposite has two main active groups such as hydroxyl $(-\mathrm{OH})$ and amino groups $\left(-\mathrm{NH}_{2}\right)$. At lower $\mathrm{pH}$, the biocomposite is positively charged due to the protonation of hydroxyl and amino groups, while the metal ions exist as anions. Similarly, the results show that percent removal of $\mathrm{Cr}^{6+}$ increases with as increase in $\mathrm{pH}$, while the minimum adsorption was observed at lower $\mathrm{pH}$ conditions. This might be due to the presence of higher concentration, and greater mobility of $\mathrm{H}^{+}$ions favored adsorption compared to the metal ions. The lower adsorption at low pH either might be due to high solubility and ionization of metal ions in the acidic medium. The increase in $\mathrm{pH}$ may cause a significant increase in the negatively charged surface area which facilitates the removal of metal ion. However, at low $\mathrm{pH}$, due to higher concentration of hydrogen ions, a resistance creates to the complexation between metal ion and active sites of the polymer. As such, an increase in $\mathrm{pH}$ leads to lower sorption. Therefore, $\mathrm{pH} \sim 7.00$ was selected for further experimental studies.

The removal of $\mathrm{Cr}^{6+}$ was studied as a function of contact time in the range of $0-720 \mathrm{~min}$. A faster adsorption was observed in the beginning followed by slow absorption pattern. The absorption equilibrium was found to be $120 \mathrm{~min}$. The initial faster absorption might be due to the fact that in the beginning, all the active sites on the surface of the sorbent were vacant; however, with an increase in contact time, the number of vacant sites decreases which results in the decrease in further sorption. Based on these results, $120 \mathrm{~min}$ was chosen as the optimum time for the rest of studies.

\subsubsection{Effect of initial concentration}

The percent removal of $\mathrm{Cr}^{6+}$ from various initial concentrations ( $1-50 \mathrm{mg} / \mathrm{L}$ ) by the biocomposite, CTS, BTF, chitin and $\mathrm{AC}$ at $\mathrm{pH} \sim 7.00$ and contact time of $120 \mathrm{~min}$ is shown in Fig. 6. The percentage removal of $\mathrm{Cr}^{6+}$ by the biocomposite, CTS, BTF, chitin and AC was found 74.60, $68.63,14.40,12.13$ and $1.65 \%$ for the initial concentration of $1 \mathrm{mg} / \mathrm{L}$ while the initial concentration of $50 \mathrm{mg} / \mathrm{L}$ indicates percent removal of $97.79,97.88,25.79,36.80$ and $23.78 \%$, respectively. As initial concentration provides an important driving force to outweigh all mass transfer resistance of metal ions between the aqueous and solid phases, an increase in initial concentration results in increased percent removal. This might be due to reduced resistance to mass transfer at higher metal ions concentration (1-50 mg/L).

\subsubsection{Sorption capacity}

The sorption capacities of the biocomposite, CTS, BTF and $A C$ were determined at an initial concentration of $50 \mathrm{mg} / \mathrm{L}$. The sorption capacities of the biocomposite, CTS, $\mathrm{BTF}$, chitin and $\mathrm{AC}$ toward $\mathrm{Cr}^{6+}$ at equilibrium time were found $12.70,12.22,3.10,5.43$ and $6.43 \mathrm{mg} / \mathrm{g}$, respectively, as shown in Fig. 7. Interestingly, the results clearly indicated that the sorption capacity of the biocomposite for $\mathrm{Cr}^{6+}$ is 1.87 times higher than $\mathrm{AC}$, and this might be due to $C T S$ is a good chelating agent for metal ions. Functional 
Fig. 6 Effect of initial concentration on the percent removal of $\mathrm{Cr}^{6+}$
Fig. 7 Sorption capacity of the biocomposite, CTS, BTF and AC towards $\mathrm{Cr}^{6+}$
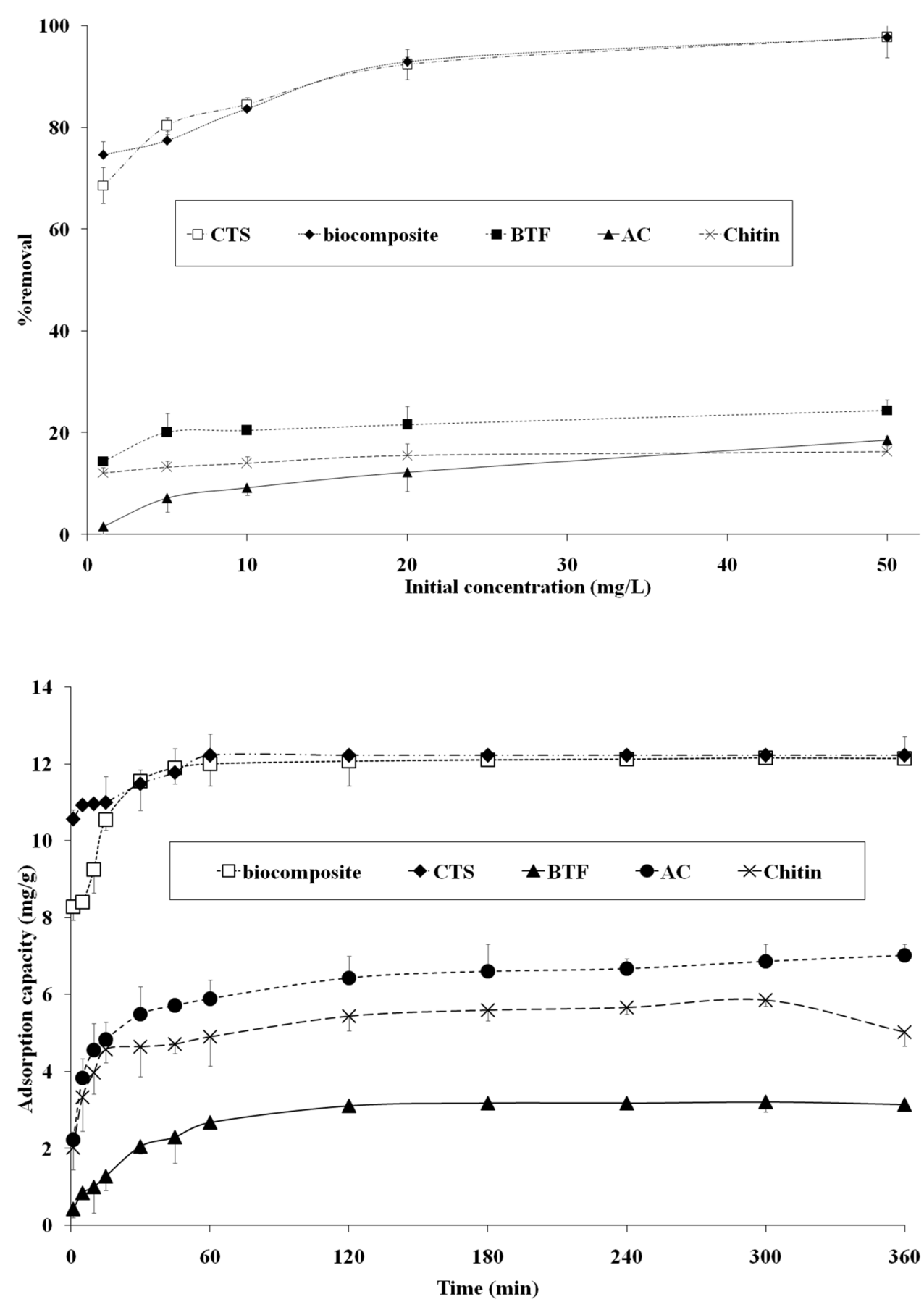

groups are the binding sites for the sorption of charged particles. In general, the increased in the surface area can significantly exposes the functional groups resulting in the increased sorption capacity. Similarly, a good matching between the sorbent pore size and ion dimensions is critical for an optimal sorption process [37]. The surface area and pore size of the materials are shown in Table 1. The results show that the surface area of the $A C$ is very greater (on average 100 times) than CTS, chitin, BTF and BTF-iCTS, but the sorption capacity of the CTS and BTF-i-CTS is
Table 1 Surface area and pore size of CTS, chitin, BTF, BTF-i-CTS and AC

\begin{tabular}{lccl}
\hline Material & $\begin{array}{c}\text { Surface area } \\
(\mathrm{BET})\left(\mathrm{m}^{2} / \mathrm{g}\right)\end{array}$ & Single point $\left(\mathrm{m}^{2} / \mathrm{g}\right)$ & Pore size $\left(\mathrm{cm}^{3} / \mathrm{g}\right)$ \\
\hline CTS & 4.2916 & 3.7294 & 0.015715 \\
BTF & 7.8188 & 3.2976 & 0.002353 \\
BTF-i-CTS & 3.7508 & 2.3392 & 0.00116 \\
Chitin & 5.0734 & 3.6381 & 0.00074 \\
AC & 702.7573 & 699.6490 & 0.453146 \\
\hline
\end{tabular}


greater than that of AC. This might be due to the chemical interaction between the $-\mathrm{NH}_{2}$ group of CTS with the metal ions. As such, CTS by itself is brittle and difficult to collect back, either the medium should be filtered or centrifuged, whereas the biocomposite is comparatively more resilient and can be removed very easily after completion of the adsorption process. The tensile strength results of the biocomposite and CTS indicate that the tensile strength of the biocomposite is improved $111 \%$. The tensile strength curves of CTS film and the biocomposite are shown in Fig. 8.

\subsubsection{Adsorption kinetics}

Pseudo-first- and pseudo-second-order kinetics were applied (initial concentration of $50 \mathrm{mg} / \mathrm{L}$ ) to obtain the rate constants. The pseudo-first-order kinetic $\log \left(q_{\mathrm{e}}-q_{\mathrm{t}}\right)$ was plotted against $t$, and a straight line with slope $\left(K_{1} / 2.303\right)$ and intercept $\left[\log \left(q_{\mathrm{e}}\right)\right]$ were obtained. However, the intercept should be equal to the equilibrium uptake of metal ions, if not then the reaction is not likely to be the first order even if correlation coefficient $\left(r^{2}\right)$ has a value of unity [38]. As such, kinetic should be pseudosecond order, if the plot of $t / q_{\mathrm{e}}$ versus $t$ gives a straight line with high linearity [38]. Therefore, the results clearly show that the data best fit the pseudo-second-order kinetic instead of pseudo-first-order kinetic. The straight line plots of pseudo-second-order kinetic for $\mathrm{Cr}^{6+}$ having $r^{2}$ of $1,1,0.997,0.998$ and 0.998 , respectively, for biocomposite, CTS, BTF, chitin and AC are shown in Fig. 9. The constants of pseudo-first order and pseudo-second order for $\mathrm{Cr}^{6+}$ onto biocomposite, CTS, BTF, chitin and AC are summarized in Table 2 . For better understanding, the data were then subjected to analyze by Langmuir and Freundlich isotherm models.

The results suggest that the adsorption of $\mathrm{Cr}^{6+}$ onto biocomposite, CTS, BTF and/or AC follows pseudo-second-order model, based on the assumption that the rate-limiting step may be chemical sorption or chemisorption involving exchange or sharing of electrons between sorbate and sorbent [39]. As CTS and BTF have two reactive functional groups $\left(-\mathrm{NH}_{2}\right.$ and $\left.-\mathrm{OH}\right)$, in acidic medium these groups are responsible for the electrostatic attraction of metal ions and some of these sites are also responsible for intra- and/or intermolecular hydrogen bonding. In conclusion, the hydroxyl and amino groups might be involved in the process of chelation with $\mathrm{Cr}^{6+}$ metal ions.
Fig. 8 Tensile strength curves of CTS (a) and biocomposite (b)
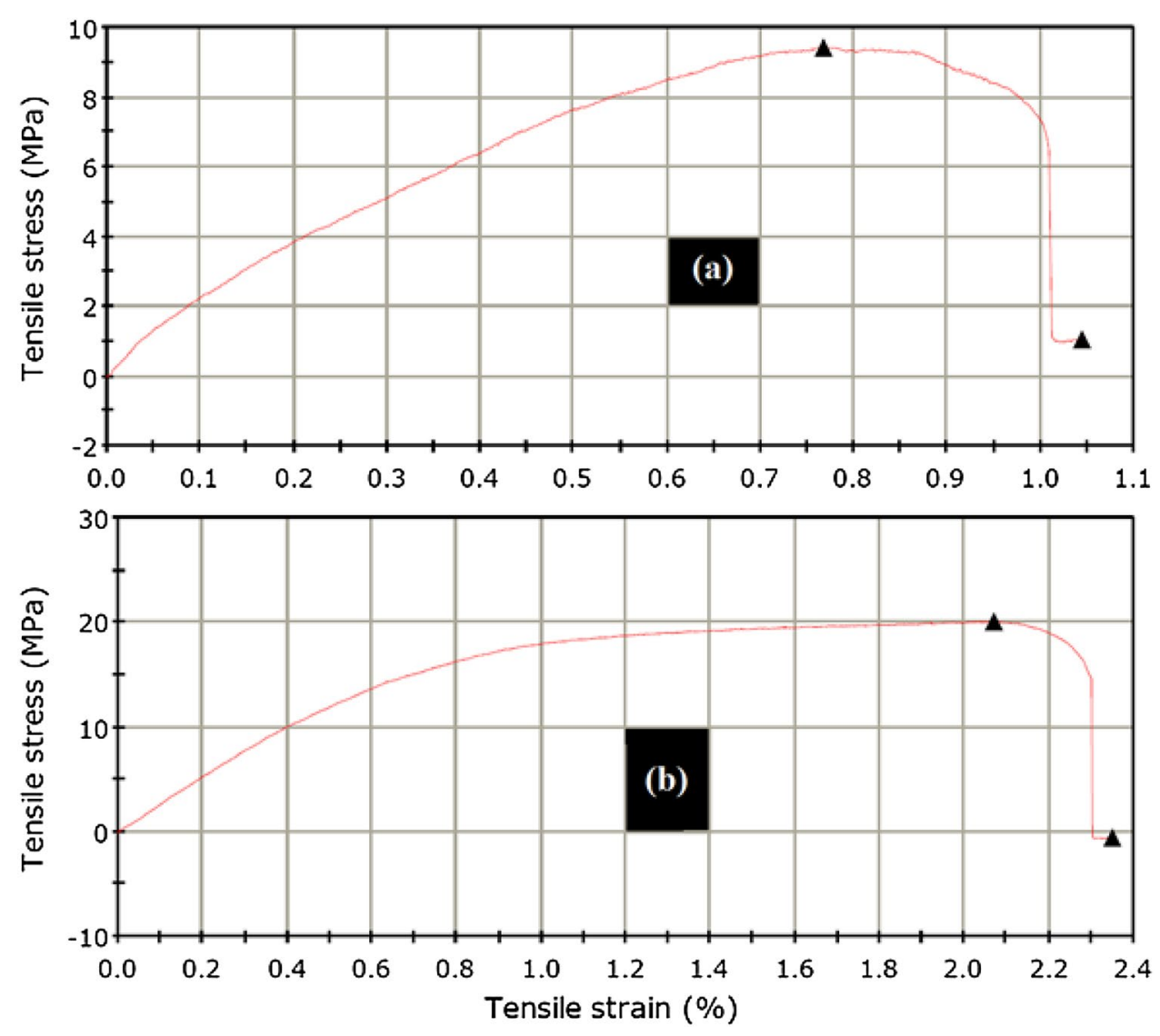
Fig. 9 Pseudo-second-order plots of $\mathrm{Cr}^{6+}$ metal ion

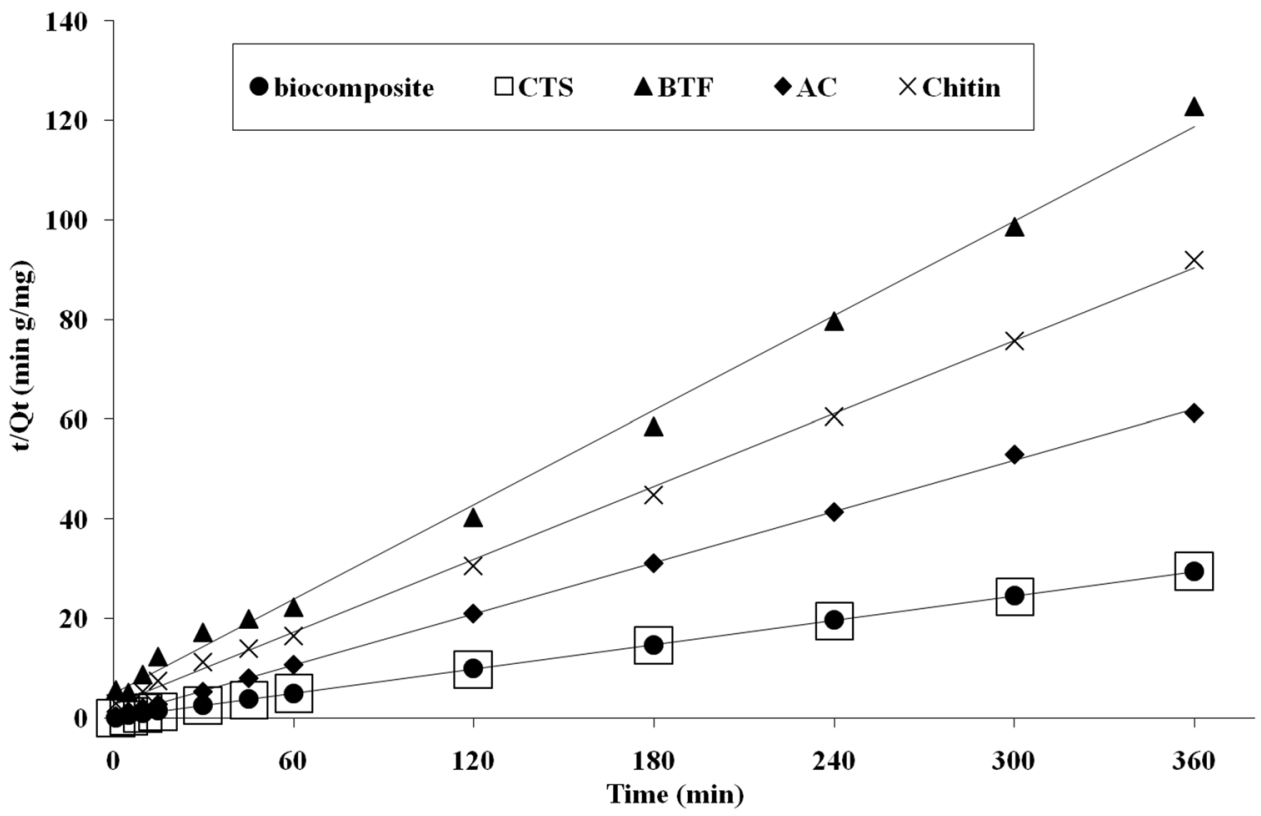

\begin{tabular}{|c|c|c|c|c|c|c|c|c|}
\hline & \multicolumn{4}{|c|}{ Pseudo-first-order kinetics } & \multicolumn{4}{|c|}{ Pseudo-second-order kinetics } \\
\hline & $r^{2}$ & $q_{\mathrm{e}}^{\mathrm{a}}$ & $q_{\mathrm{e}}^{\mathrm{b}}$ & $K_{1}$ & $r^{2}$ & $q_{\mathrm{e}}^{\mathrm{a}}$ & $q_{\mathrm{e}}^{\mathrm{b}}$ & $K_{2}$ \\
\hline Biocomposite & 0.998 & 4.792 & 12.217 & 0.0716 & 1.000 & 12.092 & 12.217 & 0.1157 \\
\hline CTS & 0.871 & 6.282 & 12.210 & 0.1214 & 1.000 & 12.225 & 12.210 & 0.1182 \\
\hline Chitin & 0.865 & 3.083 & 2.256 & 0.5643 & 0.998 & 2.876 & 2.256 & 0.0115 \\
\hline BTF & 0.844 & 5.614 & 3.055 & 0.0686 & 0.997 & 3.509 & 3.055 & 0.0081 \\
\hline$A C$ & 0.953 & 2.570 & 4.625 & 0.0276 & 0.998 & 7.127 & 4.625 & 0.0102 \\
\hline
\end{tabular}

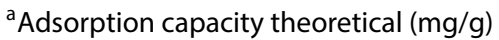

${ }^{\mathrm{b}}$ Adsorption capacity experimental $(\mathrm{mg} / \mathrm{g})$
Table 2 Adsorption kinetic constants of $\mathrm{Cr}^{6+}$

\subsubsection{Adsorption isotherms}

Langmuir and Freundlich isotherm models were used to determine the adsorption mechanism and to quantify metal ions removal capacity of the biocomposite, CTS, $\mathrm{BTF}$ and $\mathrm{AC}$ toward $\mathrm{Cr}^{6+}$. The adsorption isotherm experiments were carried out with different initial concentrations (1-50 mg/L) of $\mathrm{Cr}^{6+}$ at $27 \pm 1{ }^{\circ} \mathrm{C}$ while maintaining the sorbent dosage at a constant level.

The assumption of Langmuir isotherm model is based on the maximum adsorption corresponds to a saturated monolayer of adsorbate on the adsorbent surface. The Langmuir isotherm model was applied to the experimental data; however, the results indicated that Langmuir model is not a good fit for the adsorption process of $\mathrm{Cr}^{6+}$ onto biocomposite, CTS, chitin, BTF and AC. Therefore, Freundlich model was applied to the experimental data to get a best-fit model.

The experimental data of $\mathrm{Cr}^{6+}$ were analyzed by Freundlich isotherm model, and the results are summarized
Table 3 Constants of Freundlich model

\begin{tabular}{lllll}
\hline Materials & \multicolumn{4}{l}{ Chromium $(\mathrm{Vl})$} \\
\cline { 2 - 5 } & $R^{2}$ & $1 / n$ & $n$ & $K_{\mathrm{f}}$ \\
\hline Biocomposite & 0.988 & 1.686 & 0.593 & 2.333 \\
CTS & 0.956 & 2.096 & 0.477 & 2.259 \\
Chitin & 0.997 & 1.548 & 0.543 & 0.035 \\
BTF & 0.985 & 1.306 & 0.766 & 0.040 \\
AC & 0.993 & 1.836 & 0.544 & 0.004 \\
\hline
\end{tabular}

in Table 3. The linear plots of $\log \left(q_{\mathrm{e}}\right)$ against $\log \left(C_{\mathrm{e}}\right)$ give straight lines with a slope of $1 / n$ and an intercept of $\log \left(K_{f}\right)$. The constant $K_{\mathrm{f}}$ indicates the adsorption capacity $(\mathrm{mg} / \mathrm{g})$ while $1 / n$ is a function of the strength of adsorption in the adsorption process. If the value of $n$ is unity, then the partition between the two phases is independent of their concentration. As such, the value of $1 / n$ below unity indicates normal adsorption, while the value of $1 / n$ above one indicates cooperative adsorption [40]. The linear plots of Freundlich 
Fig. 10 Freundlich isotherm models for $\mathrm{Cr}^{6+}$ metal ion

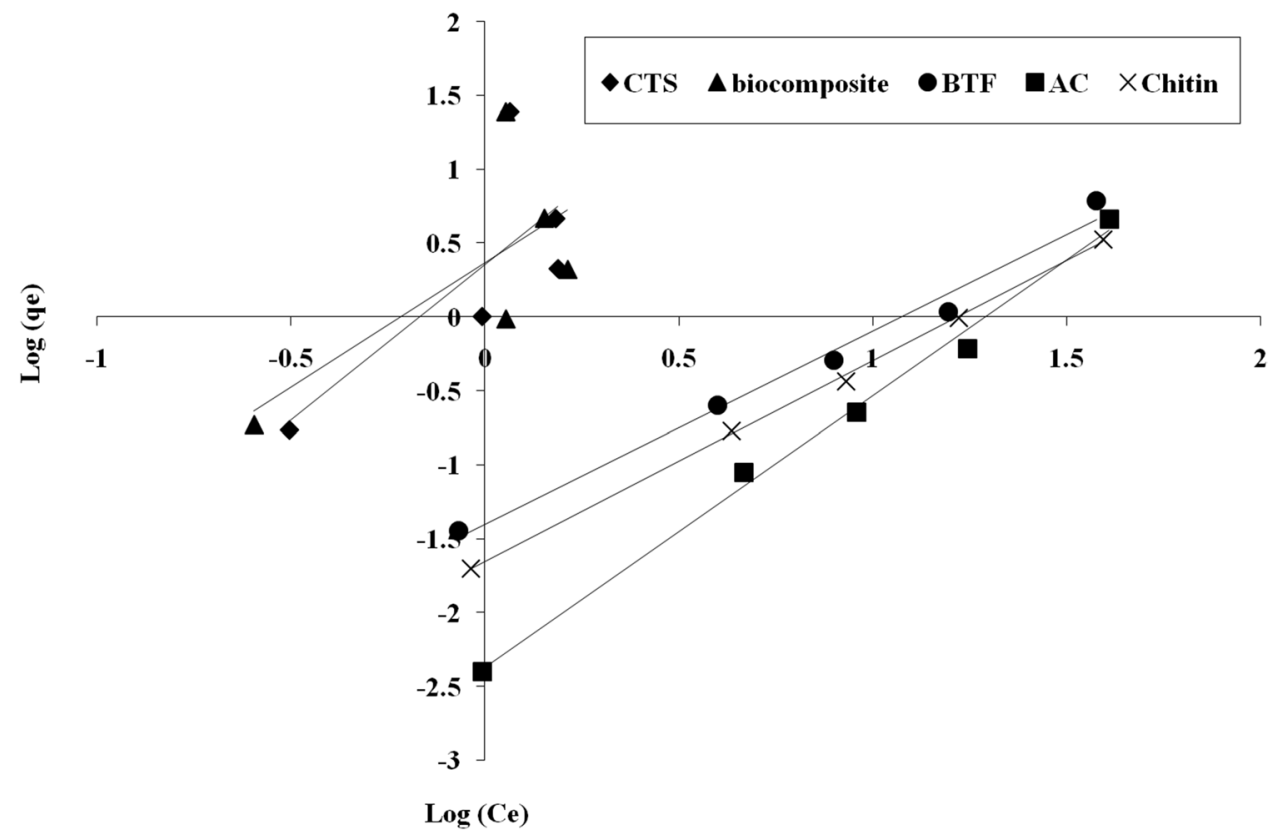

model is shown in Fig. 10. The data best fit the Freundlich model with $n$ values below unity and $1 / n$ values above one for biocomposite, CTS, chitin, BTF and AC indicates that the adsorption process is a cooperative adsorption.

\section{Conclusions}

A green biocomposite consists of BTF immobilized in CTS was prepared. The biocomposite was characterized by means of FT-IR, TGA and SEM. It was found that BTF are immobilized within CTS matrix by means of physical interaction. The water uptake results indicate that the uptake is quite faster, might be due to entrapped BTF, and creates a network which serves as a route for water penetration. The biocomposite was used for the successful removal of $\mathrm{Cr}^{6+}$. The percent removal of $\mathrm{Cr}^{6+}$ onto the biocomposite was found $97.67 \%$. It can be seen that the biocomposite indicated higher affinity toward the removal of $\mathrm{Cr}^{6+}$. This higher removal efficiency of the biocomposite toward $\mathrm{Cr}^{6+}$ might be due to complexation of $\mathrm{Cr}^{6+}$ with amine group of CTS. Chitin was used for the removal of $\mathrm{Cr}^{6+}$ to confirm the complexation of amine group which indicated, and the percent removal was observed $37.65 \%$. The results of percent removal of chitin indicate that due to lower percentage of the amine group (as compared to CTS) leading to lower removal of $\mathrm{Cr}^{6+}$. However, the interesting thing is: the biocomposite has higher sorption capacity from $\mathrm{pH} \sim 6$ to $\mathrm{pH} \sim 7$ which can help to remove metal ions from industrial aqueous wastes.

CTS by itself indicated higher affinity toward the removal of $\mathrm{Cr}^{6+}$ (97.98\%). Unfortunately, CTS is very brittle, leaches and difficult to collect back after the sorption process. The literature study reveals that $A C$ is a very commonly used sorbent for metal ions, and therefore, $\mathrm{AC}$ was tested for the removal of $\mathrm{Cr}^{6+}$ at $\mathrm{pH} \sim 7$, and the percent removal of $\mathrm{Cr}^{6+}$ was found $23.78 \%$. The percent removal of $\mathrm{Cr}^{6+}$ at $\mathrm{pH} \sim 7.00$ using biocomposite, CTS, BTF, chitin and AC was observed 97.79, 97.88, 25.79, 36.80 and $23.78 \%$, respectively. In conclusion, the removal of CTS and AC from a system is very difficult needs either filtration or centrifugation and sometimes AC blocks pores of the filter paper which requires vacuum filtration leading to high cost and time consumption, while the removal of the biocomposite is an easy and timesaving process. Therefore, the biocomposite is strongly recommended for the removal of $\mathrm{Cr}^{6+}$ from the industrial aqueous wastes.

Acknowledgements The authors would like to acknowledge Universiti Sains Malaysia (USM) for providing financial support (Grant No. 1001/PKIMIA/814124). The author (M. Rahim) is also thankful to USM and The World Academy of Sciences (TWAS) for supporting his study.

\section{Compliance with ethical standards}

Conflict of interest The authors declare that they have no conflict of interest.

\section{References}

1. Salehizadeh H, Shojaosadati SA (2003) Removal of metal ions from aqueous solution by polysaccharide produced from Bacillus firmus. Water Res 37:4231-4235

2. Fu F, Wang Q (2011) Removal of heavy metal ions from wastewaters: a review. J Environ Manag 92:407-418

\section{SN Applied Sciences}


3. Rahim M, Ullaha I, Khan A, Mas Haris MRH (2016) Health risk from heavy metals via consumption of food crops in the vicinity of District Shangla. J Chem Soc Pak 38:177-185

4. Rahim M, Imdad U, Adnan K, Haris MRHM, Nisar A (2014) Spatial distribution and risk assessment of heavy metals from drinking water in District Shangla. Sci Intern 26:1625-1630

5. Williams CJ, Aderhold D, Edyvean RGJ (1998) Comparison between biosorbents for the removal of metal ions from aqueous solutions. Water Res 32:216-224

6. Rahim M, Mas Haris MRH (2015) Application of biopolymer composites in arsenic removal from aqueous medium: a review. J Radia Res Appl Sci 8:255-263

7. Ahluwalia SS, Goyal D (2007) Microbial and plant derived biomass for removal of heavy metals from wastewater. Bioresour Tech 98:2243-2257

8. Raju GS, Haris MRHM, Azura A, Baharin A, Kartini N (2013) Effect of chitosan loading on mechanical properties, water uptake and toluene absorbency of high and low molecular weight ENR50. J Rubber Res 16:179-194

9. Gamage A, Shahidi F (2007) Use of chitosan for the removal of metal ion contaminants and proteins from water. Food Chem 104:989-996

10. Divakaran R, Paul A, Anoop K, Kuriakose V, Rajesh R (2012) Adsorption of nickel(II) and chromium(VI) ions by chitin and chitosan from aqueous solutions containing both ions. Int J Sci Tech Res 1:43-50

11. Govindarajan C, Ramasubramaniam $S$, Gomathi T, Narmadha D, Sudha P (2011) Sorption studies of $\mathrm{Cr}(\mathrm{VI})$ from aqueous solution using nanochitosan-carboxymethyl cellulose blend. Arch Appl Sci Res 3:127-138

12. Saifuddin $M$, Kumaran $P$ (2005) Removal of heavy metal from industrial wastewater using chitosan coated oil palm shell charcoal. Elect J Biotech 8:43-53

13. Schmuhl R, Krieg H, Keizer K (2004) Adsorption of $\mathrm{Cu}(\mathrm{II})$ and $\mathrm{Cr}(\mathrm{VI})$ ions by chitosan: kinetics and equilibrium studies. Water Sa 27:1-8

14. Boddu VM, Abburi K, Talbott JL, Smith ED (2003) Removal of hexavalent chromium from wastewater using a new composite chitosan biosorbent. Environ Sci Tech 37:4449-4456

15. Sağ $Y$, Aktay $Y(2002)$ Kinetic studies on sorption of $\mathrm{Cr}(\mathrm{VI})$ and $\mathrm{Cu}(\mathrm{II})$ ions by chitin, chitosan and Rhizopus arrhizus. Biochem Eng J 12:143-153

16. Kamiński W, Modrzejewska Z (1997) Application of chitosan membranes in separation of heavy metal ions. Sep Sci Tech 32:2659-2668

17. Hassan AF, Abdel-Mohsen AM, Elhadidy H (2014) Adsorption of arsenic by activated carbon, calcium alginate and their composite beads. Int J Biol Macromol 68:125-130

18. Chuang $C L$, Fan $M, X u M$, Brown RC, Sung $S$, Saha $B$, Huang $C P$ (2005) Adsorption of arsenic(V) by activated carbon prepared from oat hulls. Chemosphere 61:478-483

19. Kobya $M$, Demirbas $E$, Senturk $E$, Ince $M(2005)$ Adsorption of heavy metal ions from aqueous solutions by activated carbon prepared from apricot stone. Bioresour Tech 96:1518-1521

20. Fierro V, Torné-Fernández V, Montané D, Celzard A (2008) Adsorption of phenol onto activated carbons having different textural and surface properties. Microporous Mesoporous Mater 111:276-284

21. Chomchoey N, Bhongsuwan D, Bhongsuwan T (2013) Arsenic removal from synthetic wastewater by activated carbon-magnetic nanoparticles composite. Mater Pet Engine 8:210-216

22. Madhava Rao M, Ramesh A, Purna Chandra Rao G, Seshaiah $\mathrm{K}$ (2006) Removal of copper and cadmium from the aqueous solutions by activated carbon derived from Ceiba pentandra hulls. J Hazard Mater 129:123-129
23. Selvi K, Pattabhi S, Kadirvelu K (2001) Removal of Cr(VI) from aqueous solution by adsorption onto activated carbon. Bioresour Tech 80:87-89

24. Manjuladevi M, Manonmani S (2015) Removal of hexavalent chromium ions from aqueous solution by adsorption using activated carbon prepared from Cucumis Melo peel activated carbon. Orient J Chem 31:531-539

25. Zavvar MH, Seyedi S (2010) Kinetic and equilibrium studies on the removal of $\mathrm{Pb}$ (II) from aqueous solution using nettle ash. J Chilean Chem Soc 55:307-311

26. Kapoor A, Viraraghavan T, Cullimore DR (1999) Removal of heavy metals using the fungus Aspergillus niger. Bioresour Tech 70:95-104

27. Eren Z, Acar FN (2006) Adsorption of reactive black 5 from an aqueous solution: equilibrium and kinetic studies. Desalination 194:1-10

28. Tripathy SS, Kanungo SB (2005) Adsorption of $\mathrm{Co}^{2+}, \mathrm{Ni}^{2+}, \mathrm{Cu}^{2+}$ and $\mathrm{Zn}^{2+}$ from $0.5 \mathrm{M} \mathrm{NaCl}$ and major ion sea water on a mixture of $\delta-\mathrm{MnO}_{2}$ and amorphous FeOOH. J Colloid Interface Sci 284:30-38

29. Ahmad R, Haseeb S (2015) Competitive adsorption of $\mathrm{Cu} 2+$ and $\mathrm{Ni2}+$ on Luffaacutangula modified Tetraethoxysilane (LAP-TS) from the aqueous solution: thermodynamic and isotherm studies. Groundw Sustain Dev 1:146-154

30. Peniche C, Argüelles-Monal W, Davidenko N, Sastre R, Gallardo A, San Román J (1999) Self-curing membranes of chitosan/ PAA IPNs obtained by radical polymerization: preparation, characterization and interpolymer complexation. Biomaterials 20:1869-1878

31. Sathasivam K, Haris MRHM (2010) Adsorption kinetics and capacity of fatty acid-modified banana trunk fibers for oil in water. Water Air Soil Pollut 213:413-423

32. Alhwaige AA, Agag $T$, Ishida $H$, Qutubuddin S (2013) Biobased chitosan/polybenzoxazine cross-linked films: preparation in aqueous media and synergistic improvements in thermal and mechanical properties. Biomacromolecule 14:1806-1815

33. Sathasivam K, Haris MRHM (2011) Thermal properties of modified banana trunk fibers. J Therm Anal Calorim 108:9-17

34. Dockery CR, Pender JE, Goode SR (2005) Speciation of chromium via laser-induced breakdown spectroscopy of ion exchange polymer membranes. Appl Spectrosc 59:252-257

35. do Carmo Ramos SN, Xavier ALP, Teodoro FS, Gil LF, Gurgel LVA (2016) Removal of cobalt(II), copper(II), and nickel(II) ions from aqueous solutions using phthalate-functionalized sugarcane bagasse: mono-and multicomponent adsorption in batch mode. Indus Crops Prod 79:116-130

36. Conrad K, Hansen HCB (2007) Sorption of zinc and lead on coir. Bioresour Tech 98:89-97

37. Sun G-W, Song W-H, Liu X-J, Qiao W-M, Ling L-C (2011) Asymmetric capacitance behavior based on the relationship between ion dimension and pore size. Acta Phys Chim Sin 27:449-454

38. Hashem A, Al-Kheraije KA (2013) Chemically modified cornulaca monacanthabiomass for bioadsorption of $\mathrm{Hg}$ (II) from contaminated water: adsorption mechanism. J Environ Prot 4:280-286

39. Ho Y-S, McKay G (1999) Pseudo-second order model for sorption processes. Process Biochem 34:451-465

40. Dada A, Olalekan A, Olatunya A, Dada O (2012) Langmuir, Freundlich, Temkin and Dubinin-Radushkevich isotherms studies of equilibrium sorption of $\mathrm{Zn} 2+$ unto phosphoric acid modified rice husk. J Appl Chem 3:38-45

Publisher's Note Springer Nature remains neutral with regard to jurisdictional claims in published maps and institutional affiliations. 